\title{
Effects of subsurface cavity expansion in clays
}

\author{
S. K. A. AU* A. T. YEUNG* ${ }^{*}$, K. SOGA $†$ and Y. M. CHENG
}

\begin{abstract}
Subsurface cavity expansion in clay induced by compaction grouting can generate upward displacement of clay and/or increase in effective stress leading to consolidation, resulting in settlement compensation and/or shear strength enhancement respectively. However, the two potential benefits of subsurface cavity expansion may offset each other. Experiments and numerical simulations on the engineering behaviour of E-grade kaolin induced by subsurface pressure-controlled cavity expansion were conducted to investigate the interrelationship between compensation effectiveness and shear strength enhancement. The results of numerical simulations are in reasonably good agreement with the experimental data, indicating that the numerical simulation procedure adopted is a plausible and reliable technique to describe the engineering behaviour of clays induced by pressure-controlled cavity expansion. Effects of cavity expansion rate, cavity expansion volume, injection point spacing, and stress history on compensation effectiveness and shear strength enhancement were studied. Practical applications of the results are also proposed.
\end{abstract}

KEYWORDS: clays; grouting; laboratory tests; numerical modelling; shear strength
L'expansion d'une cavité souterraine dans l'argile peu générer un déplacement de l'argile vers le haut et/ou une augmentation de la contrainte efficace menant à une consolidation, ceci entraînant une compensation par tassement et/ou un renforcement de la résistance au cisaillement, respectivement. Il existe cependant un risque pour que les deux avantages potentiels de l'expansion de cavité souterraine s'annulent mutuellement. Des expériences et des simulations numériques portant sur le comportement mécanique du kaolin $E$ induit par une expansion de cavité souterraine en pression contrôlée ont été menées afin d'étudier les relations entre l'efficacité de la compensation et le renforcement de la résistance au cisaillement. Les résultats des simulations numériques s'accordent raisonnablement avec les données expérimentales, ceci indiquant que la procédure de simulation numérique constitue une technique plausible et fiable pour décrire le comportement mécanique des argiles induites par expansion de cavité souterraine en pression contrôlée. Les effets de la vitesse d'expansion de la cavité, du volume d'expansion de la cavité, de l'espacement des points d'injection et de l'historique de contrainte sur l'efficacité de la compensation et le renforcement de la résistance au cisaillement ont été étudiés. Des applications pratiques des résultats sont également proposées.

\section{INTRODUCTION}

Subsurface cavity expansion in soil induced by compaction grouting can generate upward displacement of the ground surface to compensate for the settlement induced by underground construction activities. The concept, theory and practice of compensation grouting are described in detail by Essler et al. (2000). The process can also increase the total stress in the soil around the expanded cavity, leading to a change of pore water pressure in the soil. As discussed by Soga et al. (2000) and Au et al. (2003), if the soil is contractive, dissipation of excess pore water pressure will result in consolidation of the soil, rendering a decrease in the compensation effectiveness of the subsurface cavity expansion. However, the decrease in void ratio of the soil leads to an increase in its shear strength. The ability of compaction grouting to densify and thus increase the strength of loose, liquefaction-susceptible soils for an industrial site near the Pajaro River at Watsonville, California, USA, is documented by Miller \& Roycroft (2004). A similar application case history is reported by Kerwin \& Stone (1997). Therefore geotechnical engineers may have to strike a balance between the compensation effectiveness and shear strength enhancement induced by subsurface cavity expansion, as these potential benefits may offset each other.

Manuscript received 21 March 2006; revised manuscript accepted 12 September 2007

Discussion on this paper closes on 1 June 2008, for further details see p. ii.

* Department of Civil Engineering, The University of Hong Kong.

$\uparrow$ Department of Engineering, University of Cambridge, UK.

$\$$ Department of Civil and Structural Engineering, The Hong Kong

Polytechnic University.
Compaction grouting can be idealised as a subsurface cavity expansion process. According to the boundary conditions of the expanding cavity, solutions to problems of cavity expansion can be broadly categorised into: (a) pressurecontrolled cavity expansion; and (b) displacement-controlled cavity expansion. Spatial distribution of pressure expanding the cavity is uniform throughout the pressure-controlled cavity expansion process, and is a function of time only, regardless of the deforming shape of the cavity. The cavity remains spherical or cylindrical throughout the displacement-controlled cavity expansion process.

Most closed-form analytical solutions describing the cavity expansion process are derived for spherical or cylindrical displacement-controlled cavity expansion in an infinite, homogeneous and isotropic continuum under isotropic stress state and either undrained or drained conditions. The soil is modelled as an elastic medium until the onset of yielding as defined by the Mohr-Coulomb failure criterion or the Camclay failure criterion. The displacements in the medium are radial everywhere, and the analysis is essentially one-dimensional. Moreover, partial drainage of the soil adjacent to the expanding cavity during the expanding stage is neglected in most of these closed-form analytical solutions (Fioravante et al., 1994; Kim et al., 1997; Guo, 2000; Au et al., 2003). These assumptions are valid in practice for the description of penetration of cone penetrometers, driven piles etc. Therefore analytical solutions to displacement-controlled cavity expansion problems may be adequate for these geotechnical engineering problems. However, the behaviour of soil during compaction grouting, installation of sand compaction piles, pile base grouting, pressuremeter tests, cratering by explosives, breaking out of anchors, and so on, is better categorised as pressure-controlled cavity expansion. For 
example, the shape of the grout bulb, the shape of the resulting plastic zone and the distribution of excess pore water pressure generated by compaction grouting would depend on the initial stress state and boundary conditions in the soil, and may not be spherical ( $\mathrm{Au}, 2001$; $\mathrm{Au}$ et al., 2006a, 2006b). Moreover, the interactive effects of neighbouring injections and the variations of drainage boundaries are neglected in these analyses. Therefore it is evident that many of these existing analytical solutions may be inadequate in solving some of these pressure-controlled cavity expansion problems.

Nonetheless, many analytical and numerical solutions are available to describe the consolidation phenomenon resulting from cylindrical or spherical cavity expansion in elastoplastic materials (e.g. Carter et al., 1979; Randolph \& Wroth, 1979; Fioravante et al., 1994; Kim et al., 1997; Burns \& Mayne, 1998, 2002; Sully et al., 1999; Guo, 2000; Kovacevic et al., 2000; Pestana et al., 2002; Jang et al., 2003; Lee et al., 2004; Einav \& Randolph, 2005). These applications in geomechanics are being developed to model the behaviour of soils during strain-holding self-boring pressuremeter tests, pressure-holding pressuremeter tests, piledriving, piezocone dissipation tests, loading of sand compaction piles, consolidation subsequent to pile installation, and so on. However, the degree of success of these applications of the cavity expansion theory in solving these geomechanical problems varies. Therefore the limitations of the theories and solutions should be noted.

This laboratory-scale experimental and numerical investigation were conducted to gain a better understanding of the consolidation deformation and shear strength enhancement characteristics of clay induced by the subsurface pressurecontrolled cavity expansion process, and to delineate the fundamental soil behaviour during and after the compaction grouting process. Laboratory-scale ideal compaction grouting experiments - that is, with no occurrence of bleeding or solid penetration during the grouting process-were performed, and numerical simulations of soil behaviour during the cavity expansion and Biot consolidation processes were conducted using finite element analyses. The consolidation behaviour of the soil around the expanding cavity was examined. The experimental data were compared with the results of numerical simulations to establish the validity of assumptions and numerical simulation procedures. Factors affecting the compensation effectiveness and shear strength enhancement are identified. Details of the laboratory and numerical investigation are reported in this paper.

\section{LABORATORY EXPERIMENTAL INVESTIGATION}

E-grade kaolin was used for the experiment. The Camclay parameters of the material obtained from triaxial tests are $\kappa=0.03, \lambda=0 \cdot 13, M=1 \cdot 05, \Gamma=2 \cdot 65, v=0 \cdot 2$ and $k=2 \times 10^{-9} \mathrm{~m} / \mathrm{s}$. A detailed description of the material is given by Elmes (1985).

Pressure-controlled cavities were expanded in clay specimens by precisely controlled injection of epoxy resin or water into a specially designed latex balloon through a multiple-hole injection needle embedded in the clay specimen to simulate an ideal subsurface compaction grouting process. The laboratory-scale experimental apparatus, which was specifically designed, fabricated and assembled, is shown in Fig. 1. Only a brief description of the apparatus and experimental procedure is given here, and readers interested in the details should refer to Au (2001), Soga et al. (2004) and Au et al. (2006a).

Clay specimens were consolidated in modified consolidometers of internal diameters $50 \mathrm{~mm}$ (denoted as R25 specimens) and $100 \mathrm{~mm}$ (denoted as R50 specimens), and height $280 \mathrm{~mm}$, accommodating specimens $100 \mathrm{~mm}$ or $200 \mathrm{~mm}$ high. The consolidation stress or vertical effective stress was exerted on the specimen by cast iron ingots through a loading frame and a piston, as shown in Fig. 1. The vertical effective stress exerted on the specimen was maintained at $140 \mathrm{kPa}$, simulating a typical depth of overburden during compaction grouting, that is, at a depth of approximately $10-15 \mathrm{~m}$ below ground surface. Clay specimens were prepared at OCRs of 1, 1.5, 2 and 5 to investigate the influence of stress history on the cavity expansion and consolidation process.

A hole was drilled at the centre of the base of the modified consolidometer to install an injection needle. Cop-

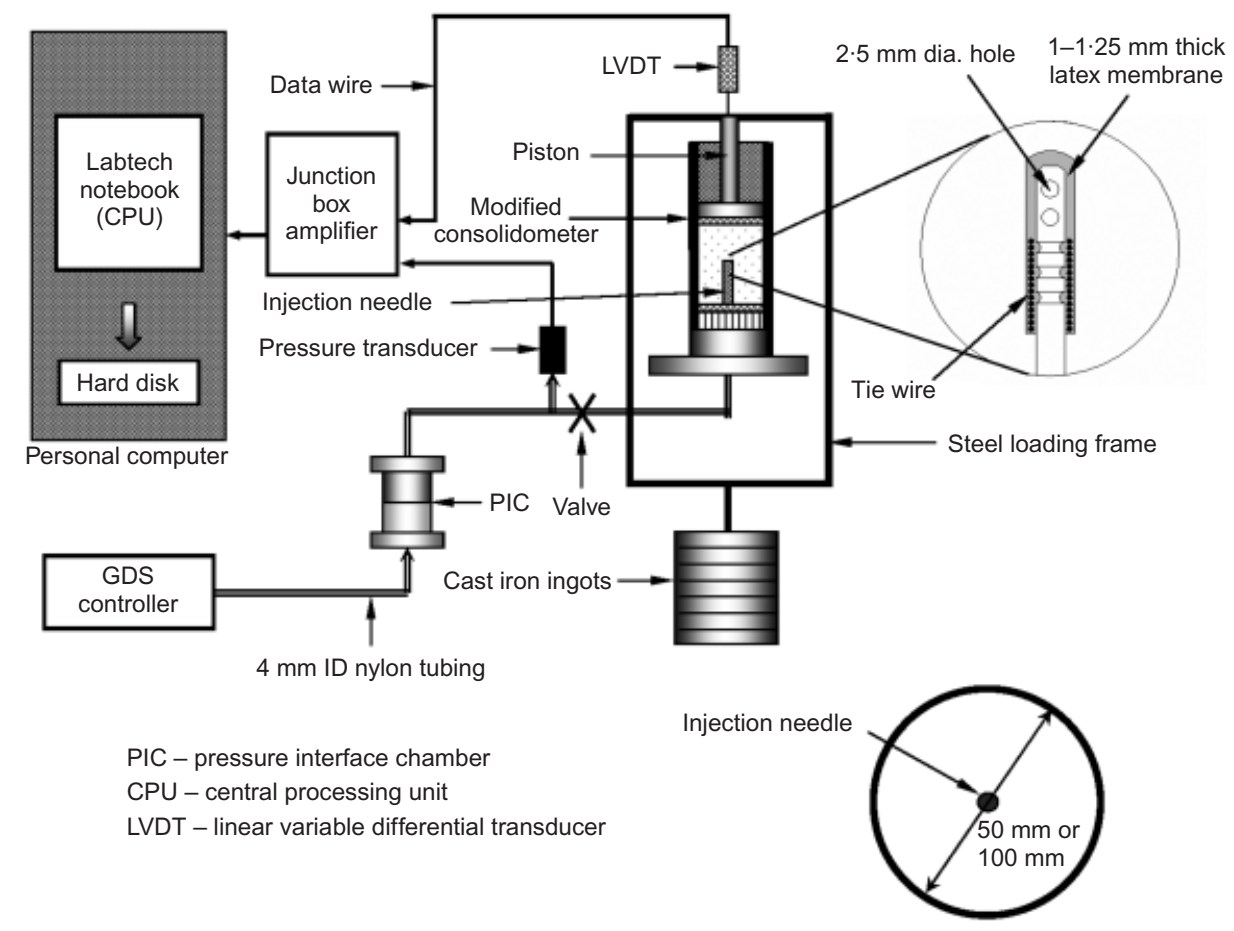

Fig. 1. Schematic of experimental set-up of grout injection 
per needles of $4 \mathrm{~mm}$ outer diameter and $3 \mathrm{~mm}$ internal diameter with the tip installed at $50 \mathrm{~mm}$ above the specimen base were used as injection needles. Two $2.4 \mathrm{~mm}$ diameter holes were drilled through the injection needle near the tip to allow horizontal injection of fluid through the needle to inflate the latex balloon, as shown in Fig. 1. Three $0.2 \mathrm{~mm}$ wide grooves were machined at a location approximately $15 \mathrm{~mm}$ below the tip of the needle, as shown. The tip of the injection needle was trimmed to allow an even spread of latex around the tip. A latex membrane 1-1.25 mm thick was installed at the tip of the injection needle to be inflated to simulate cavity expansion. After the latex membrane had been cured, the outside surface was greased to minimise any potential shearing damage induced by interactions between the clay and the latex membrane during cavity expansion. The valve installed at the entry point of the needle was then closed to ensure that no gas bubbles were trapped in the injection system. The needle was installed prior to the preparation of the clay specimen.

Fluid was injected using a GDS pressure/volume controller that can control the volumetric injection rate and limit the maximum injection pressure. The fluid could be water or epoxy resin. Epoxy resin was used to capture the final shape of the cavity. When the injection fluid was epoxy resin, a pressure interface chamber (PIC) was used to transmit the pressure from the de-aired water in the GDS controller to the injection fluid. The injection volume, vertical displacement of the top surface of the clay specimen and injection pressure were measured by the GDS, LVDT and pressure transducer respectively during the cavity expansion process. The maximum injection pressure and flow volume that can be controlled by the GDS controller are $2000 \mathrm{kPa}$ and $200 \mathrm{ml}$ with precisions of $1 \mathrm{kPa}$ and $1 \mathrm{~mm}^{3}$ respectively. The LVDT has a total stroke of $50 \mathrm{~mm}$ with a resolution of $\pm 0.002 \mathrm{~mm}$. A 70 bar Druck PDCR 510 pressure transducer was used to measure the pressure in the nylon tubing between the injection needle and the PIC, as shown in Fig. 1. For a $5000 \mathrm{~mm}^{3}$ expanded cavity in the subsurface, the surface heaves under undrained conditions for R25 and R50 specimens are theoretically $2.55 \mathrm{~mm}$ and $0.64 \mathrm{~mm}$ respectively. Methodologies to correct for the pressure losses due to friction of fluid flow within the system and expansion of the latex membrane have been developed ( $\mathrm{Au}, 2001 ; \mathrm{Au}$ et al., 2006a). Therefore the volume of the expanding cavity and the resulting pressure exerted on the clay as a function of time can be determined accurately. Post-cavity expansion settlement was measured continuously as a function of time to quantify the consolidation process subsequent to the cavity expansion process.

A series of subsurface pressure-controlled cavity expansion experiments were conducted. The experimental parameters of these laboratory experiments are listed in Table 1. The results of the experiments are compared with those of the corresponding numerical analyses to evaluate the validity of the assumptions and numerical simulation procedures. The effects of many factors, such as cavity expansion rate, cavity expansion volume and injection pressure, on the

Table 1. Parameters used in experiments

\begin{tabular}{l|c}
\hline Parameter & Values \\
\hline Overconsolidation ratio, OCR & $1,1 \cdot 5,2,5$ \\
Specimen radius, $R: \mathrm{mm}$ & 25,50 \\
Specimen height: $\mathrm{mm}$ & 100,200 \\
Rate of cavity expansion: $\mathrm{mm}^{3} / \mathrm{s}$ & $16 \cdot 7,500$ \\
Volume of cavity, $V_{\text {inj }}: \mathrm{mm}^{3}$ & $1500,2500,5000$, \\
& 10000,20000 \\
\hline
\end{tabular}

deformation characteristics of clay induced by subsurface pressure-controlled cavity expansion were studied.

\section{NUMERICAL SIMULATIONS}

A two-dimensional axisymmetric numerical model was developed to simulate the laboratory experiments so as to establish the validity of the modelling process. It includes the clay specimen and the base of the loading piston. Eightnode quadrilateral full integration consolidation elements with four integration points for pore pressure calculation and eight-node quadrilateral full integration elements (without pore pressure calculations) were adopted for the clay specimen and piston base respectively. There are 1571 elements in the mesh of the R50 specimen and 1336 elements in the R25 specimen, as shown in Fig. 2. The size of element increases with radial distance from the cavity centre, where the most rapid variations of the various parameters with distance are expected to occur. Mesh adjustments have been conducted to ensure the number of elements in the numerical model is adequate to give an acceptable degree of accuracy. The vertical cylindrical boundary and the bottom boundary were modelled as roller boundaries. Drainage boundaries were provided at the top and bottom of the specimen.

The modified Cam-clay model implemented in Abaqus (i.e. an extended version of the modified Cam-clay) was used in the analyses, as it is able to capture the plastic deformation behaviour of the clay around the expanding cavity. Details of the model are given in Abaqus (2006).

\section{Initial geostatic conditions}

Since the self-weight of the clay specimen was considerably smaller than the vertical stress exerted on the specimen, it was neglected in the analyses. The laboratory specimens were consolidated to $140 \mathrm{kPa}, 210 \mathrm{kPa}, 280 \mathrm{kPa}$ and $700 \mathrm{kPa}$ and then unloaded to $140 \mathrm{kPa}$ to prepare specimens with overconsolidation ratios of $1,1 \cdot 5,2$ and 5 respectively. In the numerical analysis, the initial stress was set at $140 \mathrm{kPa}$. The initial void ratio was set at the void ratio at $140 \mathrm{kPa}$ for the normally consolidated specimen. For the cases of OCRs of $1 \cdot 5,2$ and 5 , void ratios at $140 \mathrm{kPa}$ after rebound from the corresponding consolidation stresses were used as the initial void ratios, and the corresponding preconsolidation

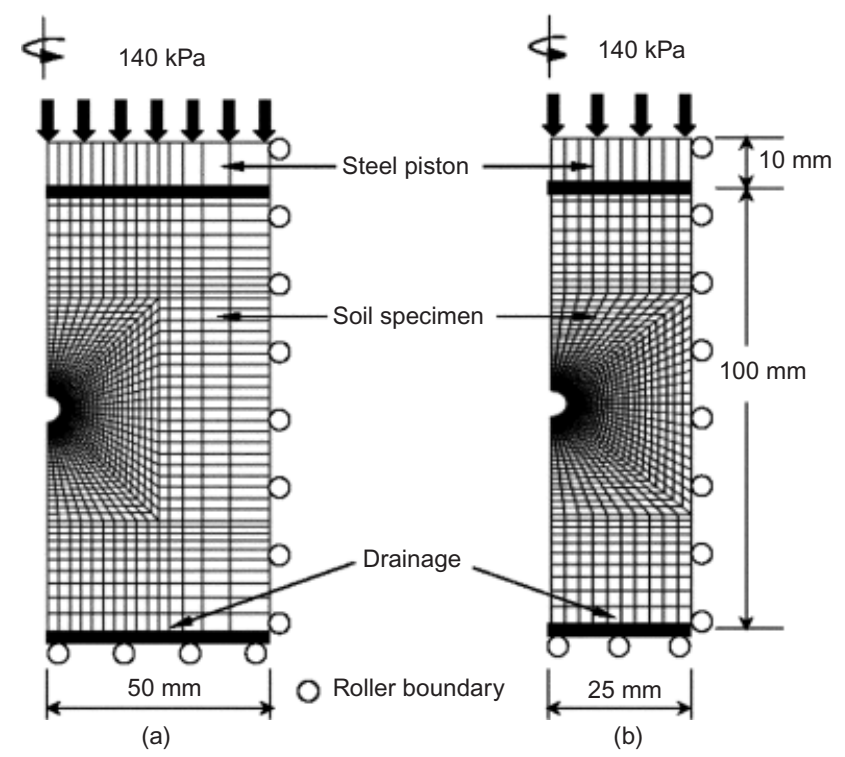

Fig. 2. Numerical model: (a) specimen R50; (b) specimen R25 
pressures were used to simulate the required OCRs. The coefficient of lateral pressure at rest, $K_{0}$, was estimated by the empirical relationship proposed by Schmidt (1966),

$$
K_{0}=\left[1-\sin \left(1.2 \times \phi_{\text {crit }}^{\prime}\right)\right] \times \mathrm{OCR}^{\sin \left(1 \cdot 2 \times \phi_{\text {crit }}^{\prime}\right)}
$$

Using equation (1), the estimated values of $K_{0}$ for OCRs of $1,1.5$ and 2 are less than unity, whereas that for an OCR of 5 is greater than unity.

The initial outside radius of the latex balloon, $3.25 \mathrm{~mm}$ ( $2 \mathrm{~mm}$ injection needle outside radius plus $1.25 \mathrm{~mm}$ balloon thickness), was used as the initial radius of the cavity. The nodal reaction forces around the cavity at equilibrium under geostatic conditions were first calculated assuming that the cavity was also filled with clay elements. The nodal reaction forces so obtained were then applied at the nodes of the cavity to maintain the initial spherical shape of the cavity under initial geostatic conditions. The clay elements within the cavity were then removed to simulate the cavity before application of the grouting pressure. The initial outside surface of the latex balloon in the experiment resembled that of an ellipsoid. Therefore the initial spherical cavity adopted in the numerical analysis was an approximation to simplify the complexity of the problem. However, as the cavity was allowed to expand and deform under a uniform spatial distribution of increasing pressure throughout the pressure-controlled cavity expansion process, the error so induced at the initial stage became negligible shortly afterwards.

\section{Pressure-controlled cavity expansion}

Simulations of the pressure-controlled cavity expansion process were conducted. After the geostatic state had been initialised, cavity expansion was simulated by rapidly increasing the pressure within the initial spherical cavity in equal steps. The volume of the cavity was calculated after each pressure step to ensure that the final experimental cavity expansion volume was not exceeded. The clay around the expanding cavity was expected to undergo large deformation. Therefore geometric non-linearity and updated Lagrangian formulations were adopted in the coupled consolidation finite element analyses. Variation of stresses, pore water pressure and void ratio in the clay were monitored during the simulations. The cavity expansion process was terminated when the expanding cavity reached the target volume, that is, the final cavity volume in the experiment. However, simulation of the Biot consolidation process was continued until completion of the consolidation process. The results of the numerical simulations are compared with the experimental data to establish the viability of the assumptions and numerical simulation procedures. Numerical simulations using the parameters listed in Table 2 were conducted to investigate various effects on the deformation characteristics of clay induced by pressure-controlled cavity expansion.

Table 2. Parameters used in simulations

\begin{tabular}{l|c}
\hline Parameter & Values \\
\hline Overconsolidation ratio, OCR & $1,1 \cdot 5,2,5$ \\
Specimen radius, $R: \mathrm{mm}$ & 25,50 \\
Specimen height: $\mathrm{mm}$ & 100 \\
Rate of cavity expansion: $\mathrm{mm}^{3} / \mathrm{s}$ & 500 \\
Volume of cavity, $V_{\text {inj: }}: \mathrm{mm}^{3}$ & $420,800,1000,1500,2500$, \\
& $5000,10000,20000$ \\
\hline
\end{tabular}

\section{RESULTS AND DISCUSSION \\ Basic relationships}

A typical curve depicting the progress of cavity expansion and consolidation during a rapid cavity expansion (grout injection) of rate $500 \mathrm{~mm}^{3} / \mathrm{s}$ to a final cavity of $5000 \mathrm{~mm}^{3}$ in an R25 specimen is shown in Fig. 3. Three distinct stages can be identified from the curve: (a) cavity expansion; (b) consolidation; and (c) equilibrium. Note that consolidation may occur during the cavity expansion stage, depending on the rate of cavity expansion and the hydraulic conductivity of the soil. Ideally, if cavity expansion occurs rapidly in the clay so that the soil deformation occurs in undrained conditions, the amount of surface heave will be equal to the volume of expansion.

The consolidation curve induced by subsurface cavity expansion is similar in shape to the plot of dial gauge readings obtained from the consolidometer test against logarithm of time, if the amount of consolidation that occurs during the cavity expansion stage is not excessive. It consists of three segments: (a) an initial curve approximating closely to a parabola; (b) a linear segment; and (c) a final curve asymptotic to the equilibrium height of the specimen. Therefore the established method being used to determine completion of consolidation can be used to analyse the experimental data collected in this investigation. However, the parabolic segment cannot be observed during the consolidation stage when a significant amount of consolidation has occurred during the cavity expansion stage.

Assuming that the one-dimensional vertical deformation measured at the top boundary of the clay specimen occurs in the specimen only, the following relationships are derived.

$$
\begin{aligned}
& \frac{\Delta \bar{e}}{1+e_{0}}=\frac{\Delta H}{H_{0}} \\
& \eta=1-\frac{\Delta H}{\Delta H_{\text {cavity }}}
\end{aligned}
$$

where $\Delta \bar{e}$ is the average change in void ratio of the specimen due to cavity expansion; $e_{0}$ is the initial void ratio of the specimen; $\Delta H=\left(H_{0}+\Delta H_{\text {cavity }}\right)-H_{\mathrm{t}}$ is the change in total height of the specimen $(\mathrm{mm}) ; H_{0}$ is the initial height of the specimen before cavity expansion $(\mathrm{mm}) ; \Delta H_{\text {cavity }}$ is the increase in height of the specimen induced by cavity expansion $=($ volume of grout injected $) /($ total cross-sectional area of the modified consolidometer); $H_{\mathrm{t}}$ is the total height of the specimen at time $t$ during the cavity expansion and consolidation stages $(\mathrm{mm})$; and $\eta$ is the compensation effectiveness ratio. Note that $\Delta H_{\text {cavity }}$ varies with time during the cavity expansion stage and becomes a constant afterwards. However, $\eta, \Delta H, H_{\mathrm{t}}$ and $\Delta e$ vary with time during both the

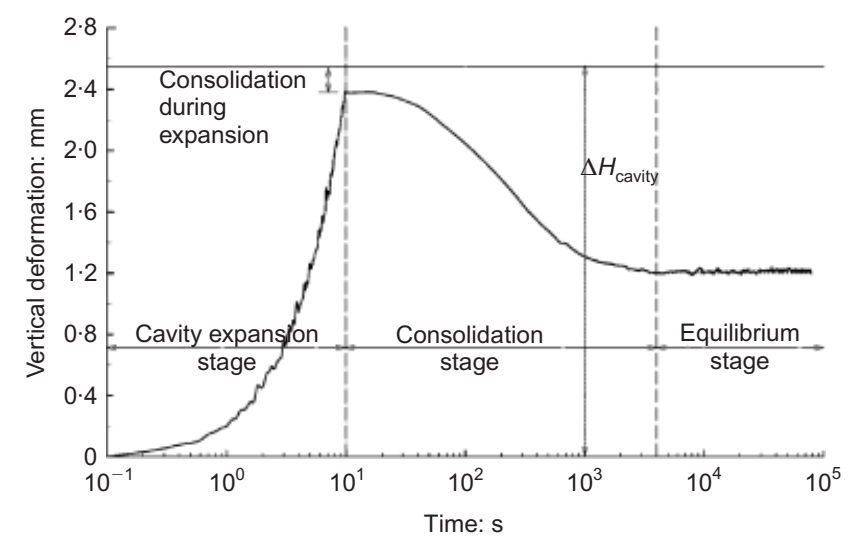

Fig. 3. Progress of cavity expansion and consolidation 
cavity expansion and consolidation stages. All these parameters are dependent on specimen size.

The parameter $\eta$ was previously denoted as 'grout efficiency' by Soga et al. (2000) and Soga et al. (2004) when the parameter was used to quantify the efficiency of compensation grouting. As the meaning of 'efficiency' can be interpreted differently in different contexts, it is considered more appropriate to denote the parameter as compensation effectiveness ratio in this paper. The relationship between compensation effectiveness ratio and the average change in void ratio can be established by combining equations (2) and (3) to give

$$
\begin{aligned}
& \Delta \bar{e}=(1-\eta) \times\left(1+e_{0}\right) \times \frac{\Delta H_{\text {cavity }}}{H_{0}} \\
& \bar{e}=e_{0}-\Delta \bar{e}
\end{aligned}
$$

where $\bar{e}$ is the average void ratio. The undrained shear strength $S_{\mathrm{u}}$ of soil subjected to any specified consolidation history and specific volume can be estimated by (Wood, 1991)

$$
S_{\mathrm{u}}=\frac{M}{2} \times \exp \left[\frac{\Gamma-(1+e)}{\lambda}\right]
$$

Therefore, neglecting the higher-order terms, the average undrained shear strength $\bar{S}_{\mathrm{u}}$ of the soil specimen can be estimated by

$$
\bar{S}_{\mathrm{u}}=\frac{M}{2} \times \exp \left[\frac{\Gamma-(1+\bar{e})}{\lambda}\right]
$$

The change in the undrained shear strength of soil resulting from the cavity expansion and consolidation processes can be described by the shear strength enhancement ratio (SSER) $\alpha$, which is defined as the ratio of the undrained shear strength of soil after consolidation to the initial undrained shear strength of the soil $S_{\mathrm{u} 0}$, that is,

$$
\alpha=\frac{S_{\mathrm{u}}}{S_{\mathrm{u} 0}}
$$

The average shear strength enhancement ratio $\left(\operatorname{SSER}_{\mathrm{ave}}\right), \bar{\alpha}$, can thus be defined by

$$
\bar{\alpha}=\frac{\bar{S}_{\mathrm{u}}}{S_{\mathrm{u} 0}}
$$

The average shear strength enhancement ratio in terms of the change in average void ratio is obtained by estimating $S_{\mathrm{u} 0}$ from $e_{0}$ using equation (8) and substituting equations (5) and (7) into equation (9) to give

$$
\bar{\alpha}=\exp \left(\frac{\Delta \bar{e}}{\lambda}\right)
$$

It can be seen from equation (10) that $\bar{\alpha}$ is greater than unity when $\Delta \bar{e}$ is greater than zero: that is, any decrease in the average void ratio will result in an increase in the average undrained shear strength of the soil specimen. Note that these parameters are dependent on specimen size. However, they are so defined for practical reasons, as geotechnical engineers are always more concerned for overall than localised engineering behaviour of soils in project sites. The volume to be used for averaging is a function of the initial distance between drainage layers, $H_{0}$, and the pattern of injection points, as discussed in detail below. Therefore the geotechnical engineer can always adjust the pattern of grout injection points to achieve the required overall engineering performance of the soil. In real-life applications there would not be a well-defined closed physical boundary to soil deformation and pore water drainage, as in this experimental study. However, the interactions between a single grout bulb and the rigid boundary are analogous to those between a grout bulb and its neighbouring grout bulbs in a closely spaced grid pattern as shown in Fig. 4. As the grout injection points are arranged in a closely spaced symmetrical array, overlapping of plastic zones or zones of excess pore water pressure can be assumed to be symmetrical. Planes of symmetry, shown as dotted lines in Fig. 4, can be defined in each of these overlapping zones. These planes of symmetry can be considered as closed roller boundaries, as there is no pore water drainage or soil displacement across the boundary. If the grouting injection points are arranged in a triangular array, the hexagonal boundary can be approximated as an equivalent circle. It is thus reasonable to simulate simultaneous multiple-point grout injection by a single injection within a circular boundary for much better computation efficiency. Therefore the results obtained in this study can be applied to gain a better understanding of the interactions between grout bulbs generated by a simultaneous multiple-point injection. In fact, the equivalent single injection hypothesis for multiple simultaneous injections has been verified by a series of laboratory tests reported by $\mathrm{Au}$ (2001) and Soga et al. (2004).

On the basis of this hypothesis, multiple simultaneous subsurface cavity expansion can be simulated by a single cavity expansion confined within an equivalent radial rigid boundary. If the radius of the rigid boundary is normalised by the equivalent radius of the cavity, a dimensionless radial boundary ratio $n_{\mathrm{r}}$ can be defined as

$$
n_{\mathrm{r}}=\frac{R-r_{0}}{r_{\mathrm{c}}-r_{0}}=\frac{R-r_{0}}{\Delta r_{\mathrm{c}}}
$$

where $R$ is the radius of the rigid boundary; $r_{0}$ is the initial equivalent radius of the cavity; $r_{\mathrm{c}}$ is the radius of the expanded cavity; $\Delta r_{\mathrm{c}}$ is the increase in equivalent radius of the cavity; and $r_{\mathrm{c}}$ is the equivalent radius of the expanded cavity, given by

$$
r_{\mathrm{c}}=\sqrt[3]{\frac{3\left(V_{0}+\Delta V\right)}{4 \pi}}
$$

where $V_{0}$ is the initial volume of the cavity $=4 \pi r_{0}^{3} / 3$; and

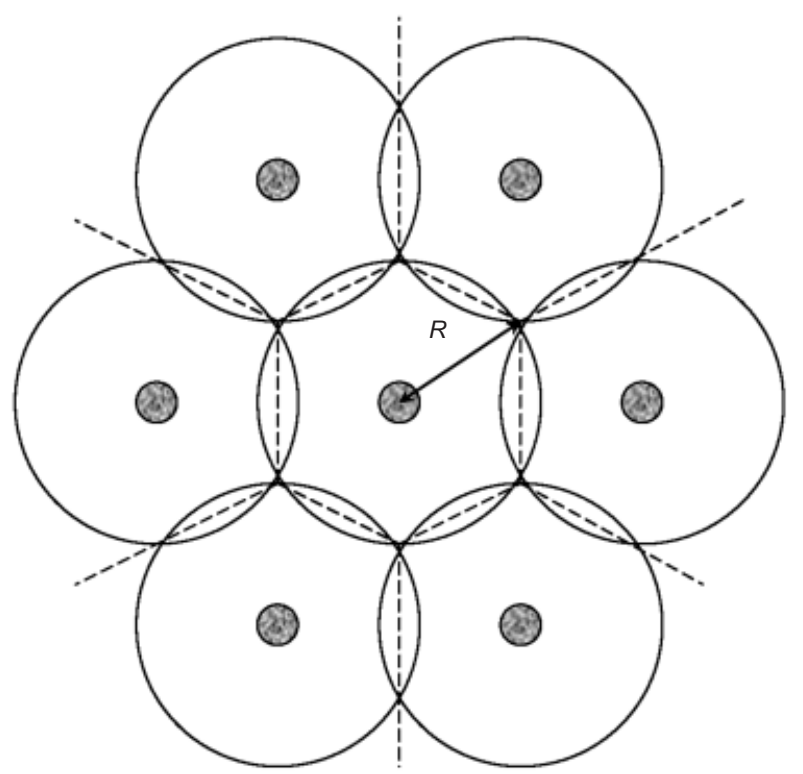

Fig. 4. Schematic of simultaneous multiple-point injection 
$\Delta V$ is the increase in cavity volume. When $n_{\mathrm{r}}$ is small, the expanded cavities are close to each other, and more interactions between expanded cavities are expected. For a single cavity expansion in an infinite space, $n_{\mathrm{r}}$ tends to infinity. The relationship between $\Delta H_{\text {cavity }}, \Delta V$ and $n_{\mathrm{r}}$ is given by

$$
\Delta H_{\text {cavity }}=\frac{\Delta V}{\pi\left(n_{\mathrm{r}} \Delta r_{\mathrm{c}}+r_{0}\right)^{2}}
$$

Substituting equations (4) and (13) into equation (10) yields

$$
\bar{\alpha}_{\mathrm{f}}=\exp \left[\frac{\left(1-\eta_{\mathrm{f}}\right)\left(1+e_{0}\right) \Delta V}{\lambda \pi H_{0}\left(n_{\mathrm{r}} \Delta r_{\mathrm{c}}+r_{0}\right)^{2}}\right]
$$

where $\bar{\alpha}_{\mathrm{f}}$ is the equilibrium average shear strength enhancement ratio; and $\eta_{\mathrm{f}}$ is the equilibrium compensation effectiveness ratio. As $R>>r_{0}$, equation (14) can be simplified to

$$
\begin{aligned}
\bar{\alpha}_{\mathrm{f}} & \approx \exp \left[\frac{\left(1-\eta_{\mathrm{f}}\right)\left(1+e_{0}\right) \Delta V}{\lambda \pi H_{0} n_{\mathrm{r}}^{2} \Delta r_{\mathrm{c}}^{2}}\right] \\
& \approx \exp \left[\frac{4\left(1-\eta_{\mathrm{f}}\right)\left(1+e_{0}\right) \Delta V}{3 \lambda \pi H_{0} n_{\mathrm{r}}^{2}}\right]
\end{aligned}
$$

The interrelationships between equilibrium average shear strength enhancement ratio $\bar{\alpha}_{\mathrm{f}}$, equilibrium compensation effectiveness ratio $\eta_{\mathrm{f}}$, radial boundary ratio $n_{\mathrm{r}}$, equivalent cavity radius $r_{\mathrm{c}}$ and initial distance between drainage layers $H_{0}$ are thus depicted in equation (15).

\section{Effect of cavity expansion rate on compensation effectiveness ratio $\eta$}

The compensation effectiveness ratio $\eta$ of normally consolidated $100 \mathrm{~mm}$ high R25 specimens measured experimentally as a function of time through the cavity expansion stage to the equilibrium stage at two cavity expansion (grout injection) rates, $500 \mathrm{~mm}^{3} / \mathrm{s}$ (rapid) and $16.7 \mathrm{~mm}^{3} / \mathrm{s}$ (slow), are shown in Fig. 5. These specimens are denoted as R25100 in the figure. The final volume of the cavity was $5000 \mathrm{~mm}^{3}$ each. The maximum compensation effectiveness ratios induced at the rapid and slow expansion rates are 0.93 and 0.62 respectively. They occurred immediately after the cavity expansion stage. The amount of consolidation occurring during the cavity expansion stage increases with decrease in cavity expansion rate, as more time is available for dissipation of excess pore water pressure during the cavity expansion stage when the expansion rate is slow. However, if the duration of cavity expansion is included as part of the consolidation period, the time required to reach the equilibrium stage is practically the same for both injection rates,

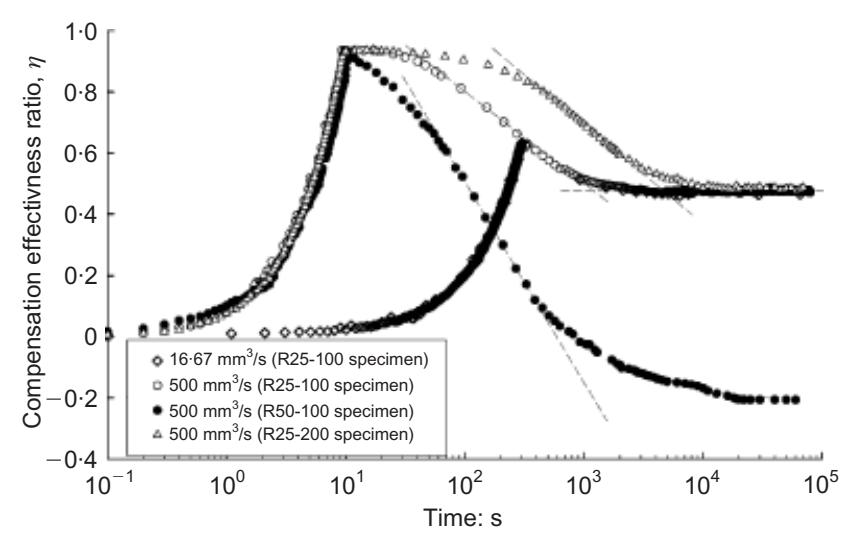

Fig. 5. Effects of cavity expansion rate and specimen size on $\eta$ indicating that the average rate of consolidation is independent of the cavity expansion rate under the given experimental conditions. The final equilibrium heights of the two specimens are practically identical, indicating that the total consolidation settlement of the specimens and consequently the equilibrium compensation effectiveness ratios $\eta_{\mathrm{f}}$ are nearly independent of the cavity expansion rate under the given experimental conditions.

\section{Effect of specimen height on compensation effectiveness ratio $\eta$}

The compensation effectiveness ratio $\eta$ of a normally consolidated R25 specimen $200 \mathrm{~mm}$ high as a function of time at the rapid cavity expansion rate, $500 \mathrm{~mm}^{3} / \mathrm{s}$, is also shown in Fig. 5. The specimen is denoted as R25-200 in the figure. The final volume of the cavity was also $5000 \mathrm{~mm}^{3}$. It can be seen that the compensation effectiveness ratios achieved at the end of the cavity expansion stage are similar to those of specimens of $100 \mathrm{~mm}$ high, indicating that they are controlled primarily by the rate of cavity expansion. The rate of consolidation of the $200 \mathrm{~mm}$ high specimen is obviously less than that of the $100 \mathrm{~mm}$ specimen as the drainage path is twice as long. If the time required for the specimen to reach equilibrium is taken as the interaction of the two linear segments of the consolidation curve, as shown in Fig. 5, the time required for the $200 \mathrm{~mm}$ high specimen to reach equilibrium is approximately four times that for the $100 \mathrm{~mm}$ high specimen. The observation is consistent with Terzaghi's theory of one-dimensional consolidation. Moreover, the equilibrium compensation effectiveness ratios $\eta_{\mathrm{f}}$ are similar, indicating that the total changes in height of the specimens throughout the subsurface cavity expansion and consolidation processes are similar, as expressed in equation (3). The observation also indicates that the zone of clay affected by the subsurface cavity expansion process and the resulting increase of excess pore water pressure in the zone are independent of specimen height under the given experimental conditions.

\section{Effect of specimen diameter on compensation effectiveness ratio $\eta$}

The effect of specimen diameter on compensation effectiveness ratio $\eta$ was also evaluated experimentally, as the effect of specimen diameter is similar to the effect of distance between grout injection points in practical applications. The compensation effectiveness ratio $\eta$ of a normally consolidated R50 specimen of $100 \mathrm{~mm}$ high as a function of time at the rapid cavity expansion rate, $500 \mathrm{~mm}^{3} / \mathrm{s}$, is also depicted in Fig. 5. The specimen is denoted as R50-100 in the figure. The final volume of the cavity was also $5000 \mathrm{~mm}^{3}$ each. It can be seen that the time required to reach equilibrium for the R50-100 specimen is similar to those of the R25-100 specimens, indicating that the diameter of the specimen does not affect the length of drainage paths, as drainage layers were provided at the top and bottom surfaces of the specimens. However, the equilibrium compensation effectiveness ratio $\eta_{\mathrm{f}}$ attained by the R50-100 specimen is considerably smaller than those attained by the R25-100 and R25-200 specimens, which shows the significant impact of the distance between the cavity and the vertical rigid boundary on the stress field induced by the subsurface cavity expansion. When the vertical rigid boundary is very close to the expanding cavity, the clay in the vicinity of the cavity is pushed upwards by the expanding cavity, resulting in a higher $\eta_{\mathrm{f}}$. When the rigid boundary is further away, the total stress in the clay is increased by the expanding cavity, resulting in a larger consolidation settle- 
ment and a lower $\eta_{\mathrm{f}}$ after the excess pore water pressure induced by the expanding cavity has dissipated.

As the consolidation settlement of the R50 specimen induced by the cavity expansion is significantly larger than those of the R25 specimens, the increase in shear strength in the R50 specimen is significantly larger than those of the R25 specimens as predicted by equation (10), at the expense of compensation efficiency.

\section{Comparison of experimental results and numerical simulations}

As the number of parameters that can be varied systematically in experiments is physically limited, numerical simulations can be used for a more comprehensive study to extrapolate limited laboratory results. However, the validity of the procedure of numerical simulations has to be established by experimental results. Therefore a comparison of the experimentally measured $\eta_{\mathrm{f}}$ and numerically simulated $\eta_{\mathrm{f}}$ for the final cavity volume of $5000 \mathrm{~mm}^{3}$ during rapid cavity expansion tests for different sizes of specimen of different OCRs is presented in Fig. 6. The dotted line represents perfect agreement of the data for easy reference. It can be observed that the simulated $\eta_{\mathrm{f}}$ are in good agreement with the measured $\eta_{\mathrm{f}}$, although the simulated $\eta_{\mathrm{f}}$ are consistently higher than the corresponding measured $\eta_{\mathrm{f}}$. Moreover, it can be seen that $\eta_{\mathrm{f}}$ increases with increase in OCR and decrease in specimen diameter. The phenomena can be delineated by analyses of numerical simulation of the cavity expansion and consolidation processes.

Excess pore water pressure distribution and shear strength enhancement ratio $\alpha$

The simulated excess pore water pressures on the horizontal plane though the centre of the cavity in the clay specimen during the consolidation stage, as a function of time and distance from the cavity centre for specimens of OCRs of 1 and 5, are shown in Figs 7 and 8 respectively. The normalised dimensionless time for consolidation, $T$, is defined as

$$
T=\frac{k t \sigma_{\mathrm{v}}^{\prime}}{\kappa \gamma_{\mathrm{w}} d^{2}\left(1+e_{0}\right)}
$$

where $k$ is the hydraulic conductivity; $t$ is the time elapsed after the cavity expansion stage; $\kappa$ is the Cam-clay swelling index; and $d$ is the approximate length of the longest possible drainage path, that is, $H_{0} / 2$. The excess pore water pressure $u$ is normalised by the effective vertical stress applied, that is, $140 \mathrm{kPa}$. The radial distance from the centre

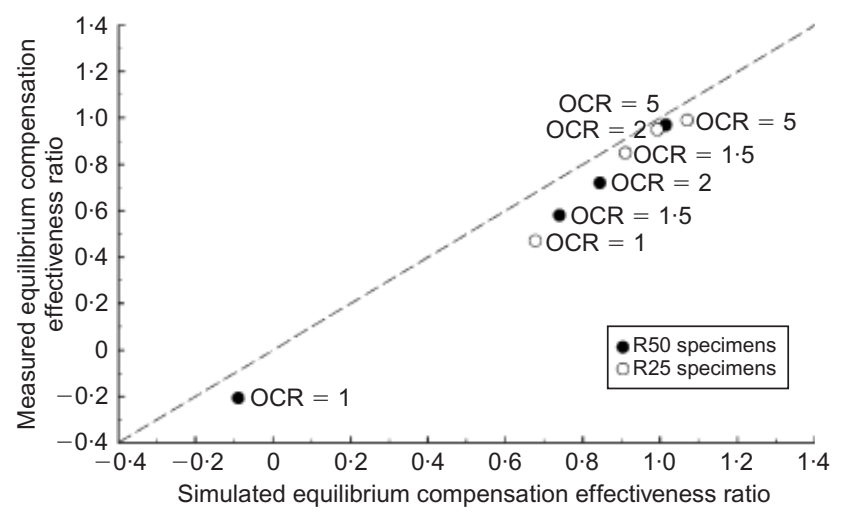

Fig. 6. Experimentally measured $\eta_{\mathrm{f}}$ against numerically simulated $\eta_{\mathrm{f}}$

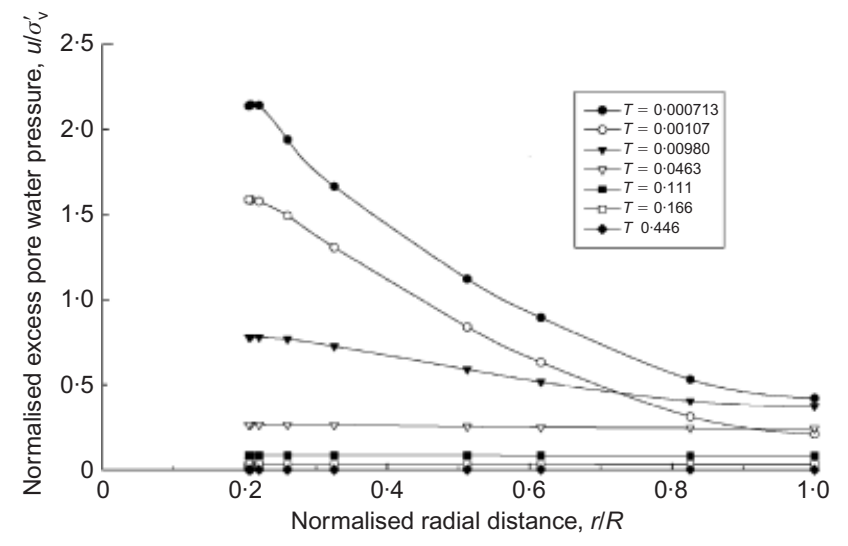

Fig. 7. Normalised time and spatial variation of normalised excess pore water pressure for a normally consolidated specimen

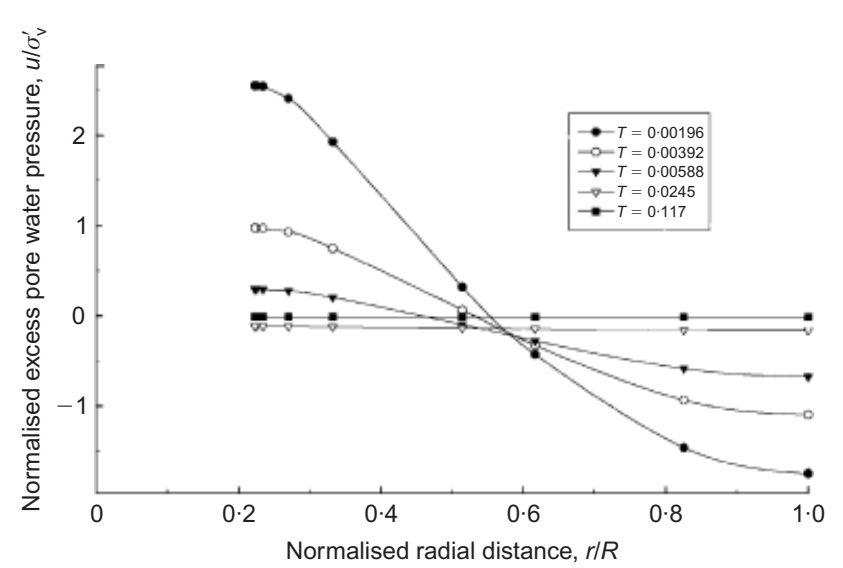

Fig. 8. Normalised time and spatial variation of normalised excess pore water pressure for a specimen with $\mathrm{OCR}=\mathbf{5}$

of the cavity, $r$, is normalised by the radius of the rigid boundary, $R$.

It can be seen in Fig. 7 that the excess pore water pressure induced by the subsurface cavity expansion in normally consolidated clay is positive everywhere, as normally consolidated clay is contractive when it is deformed by the expanding cavity. The induced excess pore water pressure decreases with time and radial distance from the centre of the cavity. Dissipation of excess pore water pressure during the consolidation stage induces significant consolidation settlement. Moreover, the shear strength of the clay increases as a result of reduction in void ratio. The variations of the equilibrium shear strength enhancement ratio $\alpha_{\mathrm{f}}$ on the vertical and horizontal planes through the centre of the cavity are depicted in Figs 9 and 10 respectively.

The excess pore water pressure induced by the expanding cavity in heavily overconsolidated clay is positive in the vicinity of the expanded cavity, but becomes negative farther from the cavity owing to the dilative behaviour of heavily overconsolidated clay when deformed by the expanding cavity, as shown in Fig. 8. During the consolidation stage, the excess positive pore water pressure in the vicinity of the cavity dissipates outwards to compensate for the negative pore water pressure, as shown in Fig. 8. As a result, the equilibrium shear enhancement ratio $\alpha_{\mathrm{f}}$ in the overconsolidated clay specimen is lower than that of the normally consolidated clay specimen as shown in Figs 9 and 10. The ratio is even less than unity in the region where $r / R$ is 


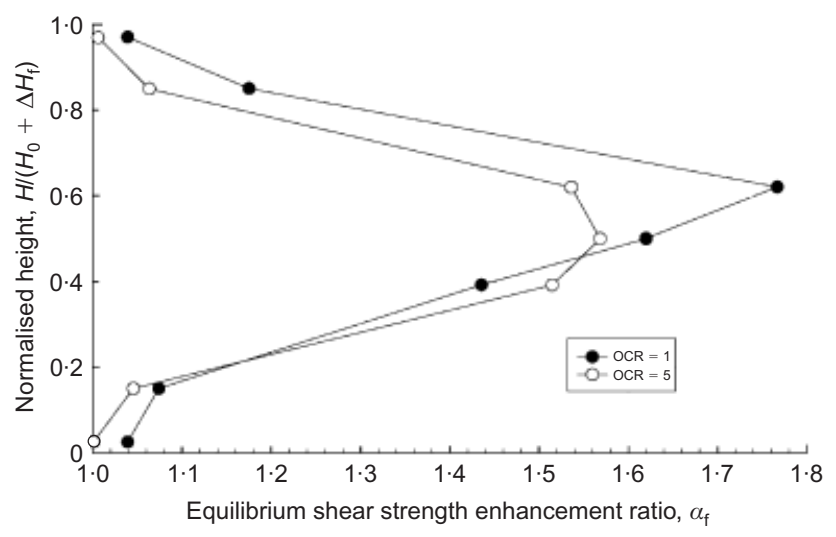

Fig. 9. Variation of equilibrium shear strength enhancement ratio with normalised height

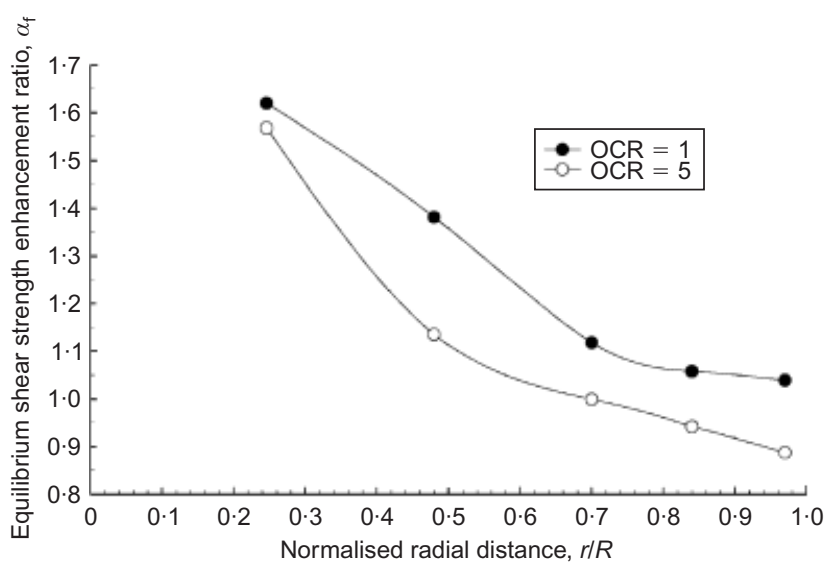

Fig. 10. Variation of equilibrium shear strength enhancement ratio with normalised radial distance

greater than approximately $0 \cdot 7$, owing to swelling of the specimen, resulting in a reduction of shear strength.

\section{Practical applications of results}

The results of this study can be used to develop a better understanding of the behaviour of clay during compaction grouting. It can be observed that the stress field, excess pore water pressure distribution and soil displacements that occur during and after pressure-controlled cavity expansion vary as a function of time. Moreover, these parameters are affected by boundary conditions, resulting in significantly different engineering behaviour of clay in terms of displacement compensation efficiency and shear strength enhancement.

A better understanding of equation (15) was developed experimentally by expansion of cavities of different volumes into clay specimens of different sizes and different OCRs. Moreover, numerical simulations have also been conducted on these experiments. The measured and simulated equilibrium compensation effectiveness ratios and equilibrium average strength enhancement ratios as a function of $n_{\mathrm{r}}$ are presented in Figs 11 and 12 respectively. In the figures, solid symbols denote experimental data and open symbols of the same shape denote the results of the corresponding numerical simulations. It can be seen in these figures that the results of the numerical simulations are in good agreement with the experimental results.

The equilibrium compensation effectiveness ratio $\eta_{\mathrm{f}}$ of the normally consolidated or lightly overconsolidated clay specimen decreases with increasing $n_{\mathrm{r}}$. Moreover, the equilibrium average shear strength enhancement ratio $\alpha_{\mathrm{f}}$ increases

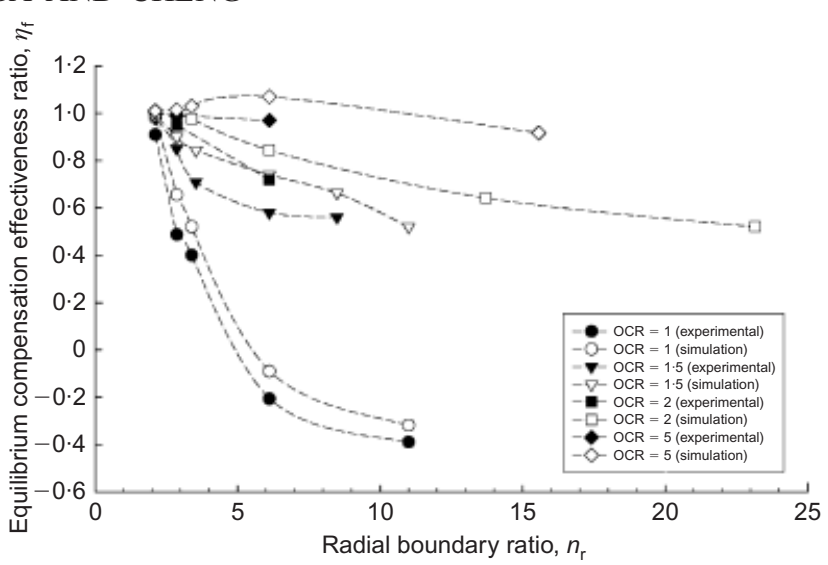

Fig. 11. Variation of equilibrium compensation effectiveness ratio with radial boundary ratio

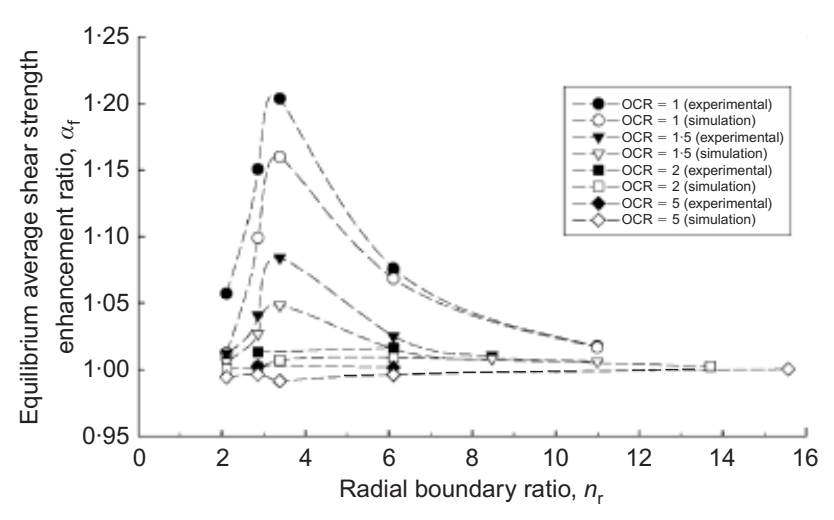

Fig. 12. Variation of equilibrium average shear strength enhancement ratio with radial boundary ratio

with $n_{\mathrm{r}}$ up to an optimum value of $n_{\mathrm{r}}$. If the primary objective of the grouting process is shear strength enhancement, the pattern of grout injection points should be designed accordingly, as further increase of $n_{\mathrm{r}}$ for operational economy results in a decrease of $\alpha_{\mathrm{f}}$. The results indicate that radial confinement in terms of lateral movement and drainage provided to normally consolidated or lightly overconsolidated clay limits the extent and magnitude of excess pore water pressure generated by subsurface cavity expansion in the clay (Soga et al., 2004). The settlement compensation efficiency of compaction grouting can be optimised by closely spaced large-volume subsurface cavity expansions. The clay is displaced upwards, as shown in Fig. 13(a), contributing primarily to settlement compensation. However, shear strength enhancement generated by subsurface cavity expansion will be minimal under such operating conditions.

The equilibrium shear strength enhancement ratio of the normally consolidated or lightly overconsolidated clay specimen can be optimised by increasing $n_{\mathrm{r}}$ to the optimum value. The value of $n_{\mathrm{r}}$ can be increased by increasing the injection point spacing or decreasing the injection volume, as depicted in equation (11). During the cavity expansion process when $n_{\mathrm{r}}$ is within this range, a larger zone of excess pore water pressure is developed, as shown in Fig. 13(b). A larger volume of soil is consolidated after dissipation of excess pore water pressure, resulting in more effective shear strength enhancement and less effective compensation efficiency. When $n_{\mathrm{r}}$ is increased beyond the optimum value, the clay distant from the expanded cavity is not affected by the cavity, leading to a lower equilibrium compensation effectiveness ratio, as depicted in Fig. 13(c).

The results indicate that subsurface cavity expansion 


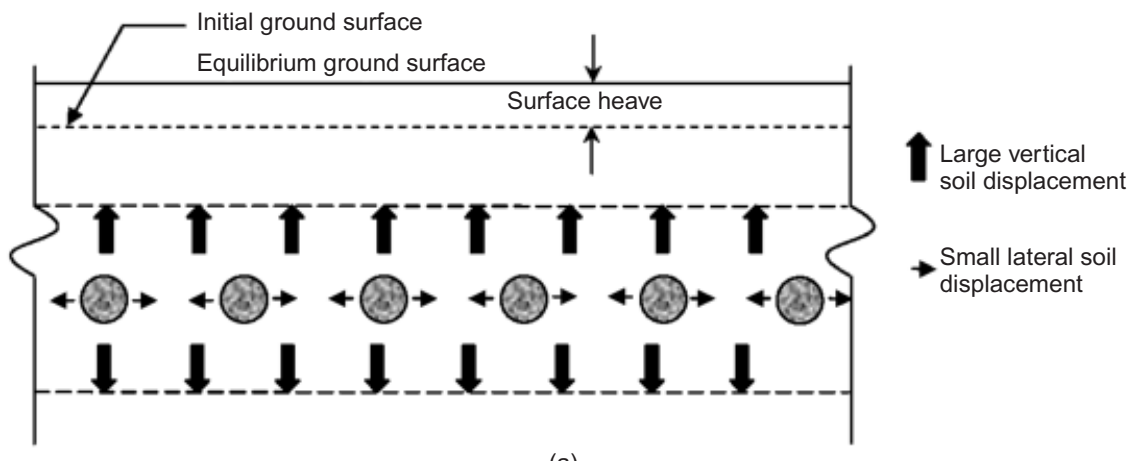

(a)

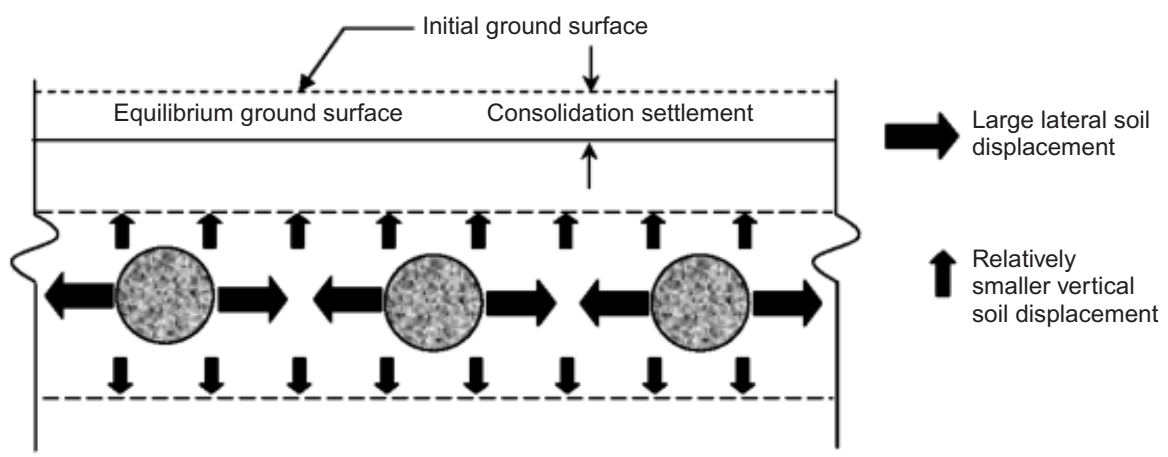

(b)

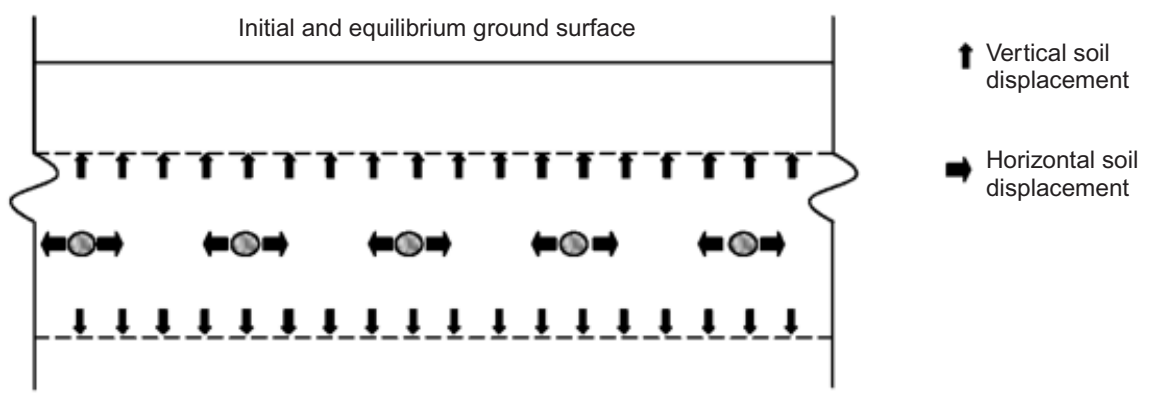

(c)

Fig. 13. Possible impacts of spatial arrangement of subsurface cavity expansions on clay behaviour: (a) effective uplifting, maximisation of settlement compensation; (b) effective compaction, maximisation of shear strength enhancement; (c) ineffective uplifting and ineffective compaction

cannot induce settlement compensation and shear strength enhancement simultaneously in normally consolidated or lightly overconsolidated clay. Depending on the required engineering performance, geotechnical engineers can optimise their designs by choice of a proper combination of injection volume and injection point spacing.

The equilibrium compensation effectiveness ratio $\eta_{\mathrm{f}}$ of the heavily overconsolidated clay specimen is practically unity and independent of $n_{\mathrm{r}}$, as shown in Fig. 11. Moreover, the shear strength enhancement is minimal, as shown in Fig. 12. Therefore subsurface cavity expansion is a very effective technique in settlement compensation in heavily overconsolidated clay, but a very ineffective technique in shear strength enhancement.

\section{CONCLUSIONS}

Laboratory experiments were carried out to examine the effects of subsurface pressure-controlled cavity expansion on settlement compensation and shear strength enhancement in clays of different overconsolidation ratios. Numerical simulations of these experiments were also performed. The follow- ing conclusions can be drawn from the experimental and numerical studies.

(a) The engineering behaviour of clay under the influence of pressure-controlled subsurface cavity expansion can be separated in two distinct stages: (i) cavity expansion and (ii) consolidation. However, significant consolidation can occur in the cavity expansion stage if the injection rate is relatively slow.

(b) The subsurface cavity expansion can induce settlement compensation and shear strength enhancement in clays. However, the two effects offset each other. In general, maximisation of the extent and magnitude of excess pore water pressure induced by the expanding cavity in clay maximises the consolidation settlement, thus maximising the enhancement of shear strength, but minimising the efficiency of settlement compensation. Minimisation of the extent and magnitude of excess pore water pressure induced by the expanding cavity in clay maximises the efficiency of settlement compensation. However, the enhancement of shear strength is minimal.

(c) The shear strength of normally consolidated or lightly 
overconsolidated clays (OCR up to approximately 1.5) can be enhanced effectively by a proper combination of injection volume and injection point spacing. When the injection point spacing is too close, or when the injection volume is too large, the clay will be displaced upwards by the expanding cavity, resulting in reduced shear strength enhancement. When the injection point spacing is too large, or when the injection volume is too small, the excess pore water pressure induced in the clay is too small to induce a reasonable shear strength enhancement.

(d) Effective settlement compensation can be achieved by closely spaced large-volume subsurface cavity expansions in normally consolidated or lightly overconsolidated clays.

(e) Effective settlement compensation can always be achieved by subsurface cavity expansions in heavily overconsolidated clays. However, shear strength enhancement induced by subsurface cavity expansions in heavily overconsolidated clays is minimal owing to the dilative behaviour of the clay.

\section{ACKNOWLEDGEMENTS}

Financial support provided by Research Grants Council Project Nos. HKU 1178/03E and HKU 7193/05E of the Hong Kong Special Administrative Region Government for this project is gratefully acknowledged. However, the contents of this paper do not necessarily reflect the views and policies of the Hong Kong Special Administrative Region Government, nor does the mention of trade names and commercial products constitutes endorsement or recommendation for use. The writers are also grateful to the diligent work of the assessor handling the review of the paper, and the two anonymous reviewers. Their careful reviews, and constructive comments and suggestions, have greatly improved the quality of the manuscript.

\section{REFERENCES}

Abaqus (2006). ABAQUS theory manual. ABAQUS, Inc. http: //abaqus-Is2.aeromech.usyd.edu.au:2080/v6.6/books.stm/default. htm

Au, S. K. A. (2001). Fundamental study of compensation grouting. $\mathrm{PhD}$ thesis, Department of Engineering, University of Cambridge, UK.

Au, S. K. A., Soga, K., Jafari, M. R., Bolton, M. D. \& Komiya, K. (2003). Factors affecting long-term efficiency of compensation grouting in clay. J. Geotech. Geoenviron. Engng ASCE 129, No. 3, 254-362.

Au, S. K. A., Soga, K. \& Yeung, A. T. (2006a). A new laboratory apparatus for grout injection studies. Geotech. Test. J. ASTM 29, No. 2, 95-101.

Au, A. S. K., Yeung, A. T. and Soga, K. (2006b). Pressurecontrolled cavity expansion in clay. Can. Geotech. J. 43, No. 7, 714-725.

Burns, S. E. \& Mayne, P. W. (1998). Monotonic and dilatory porepressure decay during piezocone tests in clay. Can. Geotech. J. 35, No. 6, 1063-1073.

Burns, S. E. \& Mayne, P. W. (2002). Analytical cavity expansioncritical state model for piezocone dissipation in fine-grained soils. Soils Found. 42, No. 2, 131-137.
Carter, J. P., Randolph, M. F. \& Wroth, C. P. (1979). Stress and pore pressure changes in clay during and after the expansion of a cylindrical cavity. Int. J. Numer. Anal. Methods Geomech. 3, No. 3, 305-322.

Einav, I. \& Randolph, M. F. (2005). Combining upper bound and strain path methods for evaluating penetration resistance. Int. J. Numer. Methods Engng 63, No. 14, 1991-2016.

Elmes, D. R. (1985). Creep and viscosity in two kaolin clays. PhD thesis, Department of Engineering, University of Cambridge, UK.

Essler, R. D., Droff, E. R. \& Falk, E. (2000). Compensation grouting: concept, theory and practice. In Advances in grouting and ground modification (eds R. J. Krizek and K. Sharp), Geotechnical Special Publication No. 104, pp. 1-15. Reston, VA: ASCE.

Fioravante, V., Jamiokowski, M. \& Lancellotta, R. (1994). An analysis of pressuremeter holding tests. Géotechnique 44, No. 2 , $227-238$.

Guo, W. D. (2000). Visco-elastic consolidation subsequent to pile installation. Comput. Geotech. 26, No. 2, 121-140.

Jang, I. S., Chung, C. K., Kim, M. M. \& Cho, S. M. (2003). Numerical assessment on the consolidation characteristics of clays from strain holding, self-boring pressuremeter test. Comput. Geotech. 30, No. 2, 121-140.

Kerwin, S. T. \& Stone, J. J. (1997). Liquefaction failure and remediation: King Harbor Redondo Beach, California. J. Geotech. Geoenviron. Engng ASCE 123, No. 8, 760-769.

Kim, Y. S., Lee, S. R. \& Kim, Y. T. (1997). Application of an optimum design technique for determining the coefficient of consolidation by using piezocone test data. Comput. Geotech. 21, No. 4, 277-293.

Kovacevic, N., Potts, D. M. \& Vaughan, P. R. (2000). The effect of the development of undrained pore pressure on the efficiency of compaction grouting. Géotechnique 50, No. 6, 683-688.

Lee, F. H., Juneja, A. \& Tan, T. S. (2004). Stress and pore pressure changes due to sand compaction pile installation in soft clay. Géotechnique 54, No. 1, 1-16.

Miller, E. A. \& Roycroft, G. A. (2004). Compaction grouting test program for liquefaction control. J. Geotech. Geoenviron. Engng $A S C E$ 130, No. 4, 355-361.

Pestana, J. M., Hunt, C. E. \& Bray, J. D. (2002). Soil deformation and excess pore pressure field around a closed-ended pile. J. Geotech. Geoenviron. Engng ASCE 128, No. 1, 1-12.

Randolph, M. F. \& Wroth, C. P. (1979). An analytical solution for consolidation around a driven pile. Int. J. Numer. Anal. Methods Geomech. 3, No. 3, 217-230.

Schmidt, B. (1966). Discussion. Earth pressures at rest related to stress history. (Brooker, E. W. \& Ireland, H. O.). Can. Geotech. J. 3, No. 4, 239-242.

Soga, K., Au, S. K. A., Jafari, M. R. \& Bolton, M. D. (2004). Laboratory investigation of multiple grout injections into clay. Géotechnique 54, No. 2, 81-90.

Soga, K., Bolton, M. D., Au, S. K. A., Komiya, K., Hamelin, J. P., Van Cotthem, A., Buchet, G. \& Michel, J. P. (2000). Development of compensation grouting modelling and control system. In Geotechnical aspects of underground construction in soft ground, Proceedings of the International Symposium on Underground Construction in Soft Ground: IS-Tokyo '99 (eds O. Kusakabe, K. Fujita and Y. Miyazaki), pp. 425-430. Rotterdam: A. A. Balkema.

Sully, J. P., Robertson, P. K. \& Campanella, R. G. (1999). An approach to evaluation of field CPTU dissipation data in overconsolidated fine-grained soils. Can. Geotech. J. 36, No. 2, 369-381.

Wood, D. M. (1991). Soil behaviour and critical state soil mechanics. Cambridge: Cambridge University Press. 